\title{
Los gabinetes de prensa en instituciones y empresas. Información vs. Relaciones Públicas
}

Recibido: 05 de diciembre de 2012

Aceptado: 01 de agosto de 2013

Publicado: 29 de noviembre de 2013
Fernando Moya Hiniesta

fsegundo@us.es

Universidad de Sevilla (España)

Resumen: La labor de los gabinetes de prensa en instituciones y empresas, la sustitución de las fuentes de información y el modo operativo en notas de prensa, comunicados, ruedas de prensa, etc., y en general todo el trabajo anterior y posterior para garantizar el éxito informativo son pormenorizados, vinculándolos a una estructura organizativa superior en la comunicación. Todo ello desde la perspectiva teórica y praxis profesional, contadas con ejemplos vivos e históricos, y en el que no es menos importante la labor de anonimato en el que se sitúan, en tanto firma de lo publicado, las personas al frente de estos dispositivos. Se analizan asimismo otras facetas propias de los gabinetes de prensa, más allá de las labores propias de redacción de informaciones, pero de igual interés para las entidades públicas y privadas. Y singularmente el rol que desempeñan en las campañas políticas.

Palabras clave: Fuentes de información, conferencia de prensa, artículo de opinión, seguimiento de medios, declaración y contradeclaración, comunicados, gestión de comunicación.

Abstract: The work of the press offices in institutions and enterprises, the substitution
of sources of information and the operating mode in press releases, press conferences,
etc., and generally all previous and subsequent work to ensure informative success,
are detailed by linking them to a higher organizational communication. All this from
the theoretical perspective and professional praxis, told with vivid, and historical,
examples, and in which no less important is the work of anonymity in which are
located, as authors of the released issues, the people in charge of these devices. Other
aspects specific to the press offices are also discussed, beyond the tasks associated with 
writing reports, but of equal interest to public and private entities. And singularly the role they play in political campaigns.

Key words: Information Sources, Press Conference, Opinion Article, Press Clip, Declaration and Counterdeclaration, Press Release, Communication Management.

\section{Introducción}

Los gabinetes de prensa o de comunicación según amplíen sus funciones, trabajen de manera aislada o dentro de un organigrama mayor dentro de las estructuras institucionales, como labor directiva o de management de las compañías (Villafañe, 1996), lanzan informaciones a los medios, propias en su redacción del papel de periodista. Así que en las redacciones de periódicos, en emisoras de radio, en los fax, telex, e-mail de nuestras televisiones, entre las noticias que llegan en secciones nacionales, regionales o locales, es corriente que aparezcan múltiples convocatorias de ruedas de prensa, declaraciones, manifestaciones, contra-manifestaciones, opiniones puntuales, etc. que proceden de gabinetes de prensa.

A medida que estos van tecnificándose han pasado de la "galaxia Gutemberg", o mejor de la "presión Gutemberg" (caso de los gabinetes de prensa políticos o institucionales, donde el líder o el despacho de turno no valora aquello con lo que no se desayuna de manera impresa), a elaborar noticias para radio y televisión, hoy también Internet, inclusive teniendo su propio estudio de producción, trascendiendo el mero formato de gabinete de prensa.

Lo que nos ocupa en este trabajo es su incidencia, contenidos y presentación formal. El resultado de todo ello es que de la comunicación de ideas/propaganda, propia de los partidos $^{1}$, pasamos muy frecuentemente a la de hechos. Así, los gabinetes de prensa se convierten en fuentes de información, ávidos por traspasar la barrera de las redacciones y sustituir en estas noticias (plenamente elaboradas) a los profesionales del medio.

Tras estas consideraciones, me permito definir los gabinetes de prensa como fuentes de información, organizada y estructurada técnicamente, que elabora y selecciona noticias para prensa, radio, televisión y sus respectivas secciones informativas; destinados como intermediarios a cubrir las necesidades de comunicación de organizaciones institucionales o privadas, culturales, sociales, empresariales, entre otros, con el fin de informar e influir en la opinión pública, mediante comunicados, declaraciones, ruedas de prensa o artículos de opinión y referidos a estrategias globales o hechos puntuales.

No todos los gabinetes de prensa consiguen el "éxito informativo". Su incidencia depende de varios factores tales como:

1 Desantes (1974) distingue la comunicación de "juicios-opinión” y la de "hechos-noticias". 
- Relevancia de la organización representada.

- Prestigio social.

- Organización profesional del gabinete.

- Trato personal del jefe de gabinete con los periodistas de las secciones.

- Prestigio profesional del jefe de gabinete.

- Forma de elaboración de la noticia con documentación contextuada de la misma.

- Utilización adecuada de las diferentes técnicas empleadas por los diferentes medios.

- Selección adecuada de los medios en función de la noticia.

- Dosificación de las noticias de interés.

- Breve seguimiento de que la noticia ha llegado a la sección y persona pertinente, y conversación sobre la misma.

- Acuerdo de colaboración entre la organización representada y el medio.

Pormenoricemos estos factores. Parece claro que la relevancia de una organización, poder político o empresa, genera más posibilidades de acceso al medio y por tanto mayor presencia mediática a través del gabinete. Pero puede ocurrir que desde una ONG (teóricamente con menores posibilidades de acceso a los medios) se utilicen mecanismos adecuados comunicativos y se sitúen noticias por el mero hecho de saberlas transmitir en el momento adecuado y con la profesionalidad requerida.

El trato personal del jefe de gabinete con los periodistas de las secciones es un factor de gran importancia. Todas las relaciones entre medios, instituciones o empresas son relaciones humanas. Por lo que, además de formar parte de las esferas cotidianas de nuestros contactos y sentimientos con los demás, las relaciones de los gabinetes con los medios tiene mucho de Relaciones Públicas, por tanto hay que esmerar el trato y ser porosos a las circunstancias personales de los periodistas a los que nos dirigimos ${ }^{2}$.

En la misma medida de importancia, hay que señalar el prestigio profesional del jefe de gabinete. Un periodista respetado por su trabajo, seriedad y credibilidad, tendrá más oportunidad de colocar los mensajes e informaciones que otro que no tenga igual prestigio. El periodista del medio concederá fiabilidad a una información documentada que aligere el trabajo en la redacción del medio.

La utilización adecuada de las distintas técnicas de los medios incide, asimismo, en estar presente informativamente. Facilitar la labor a los periodistas es esencial. Si damos una nota de prensa para el medio impreso no será igual su redacción que para la radio o la televisión. En caso de tener que lanzarla de manera única, una fórmula adecuada sería la del subrayado o poner en negrilla los destacados que serán recogidos por radio o televisión.

La forma de elaboración de la noticia con documentación contextuada, unido al prestigio

2 Una onomástica, un alumbramiento o una enfermedad serán objeto de preocupación e interés por parte del gabinete. Fomentar las relaciones es muy de agradecer a la hora de conseguir traspasar la barrera del medio para situarse como noticia. 
profesional, permitirá que al recibirse la información en las redacciones, los periodistas no tengan que buscar documentación para contextualizar la noticia. Facilitar el trabajo de esta forma permite un mayor acceso a los medios. No hay que olvidar que en las redacciones se trabaja con prisas y a menudo un mismo redactor tiene que lanzar varias noticias: la que está más elaborada tiene mayor posibilidad de estar en el medio y sobre todo de estar tal como la elaboró el gabinete, lo que da mayor garantía de éxito para la organización representada.

La selección adecuada de los medios, en función de la noticia, permite mayor eficiencia y sobre todo ahorro de tiempo para el gabinete y el medio. La información debe ir dirigida sólo al lugar o sección de interés, y más concretamente al periodista responsable de la redacción de esa sección. Acaso también a su jefe de sección.

Dosificar las noticias es muy conveniente. A menudo, las organizaciones tienden a creer que todo lo que realizan sus áreas de comunicación es noticiable. No por mucho enviar comunicados, notas de prensa y declaraciones se consiguen mayores resultados. Bien al contrario, en la redacción del medio, una sobrecarga de información puede ir en detrimento de que se publique lo que realmente es noticioso y de relevancia para la organización.

Por tanto, el dar un mayor número de noticias no garantiza la incidencia. Un bombardeo constante de mensajes puede provocar falta de credibilidad. Además (sucede con frecuencia en organismos públicos con tendencia a la funcionarización, donde se programan los e-mails) no hay que conformarse con el envío de la información al medio que hayamos seleccionado y a su redactor.

Es necesario un breve seguimiento de la noticia y confirmar si ha llegado a la sección pertinente. En las redacciones es muy habitual que se pierdan las informaciones por la rapidez que exige el trabajo informativo. Un periodista que ha recogido lo que es de otra sección puede desecharlo. Por lo que una vez enviado hay que asegurar su efectiva recepción. Momento muy oportuno para explicar y persuadir sobre la importancia de lo que hemos escrito y enviado.

La posibilidad de establecer acuerdos de colaboración entre la organización representada y el medio puede estar relacionada con la publicidad a emitir (con dossier o espacios especiales), con la divulgación de ofertas de los medios, con descuentos a los trabajadores del medio o con cualquier otro tipo de acuerdo, dependiendo de la empresa o institución y del propio medio de difusión.

\section{Naturaleza y funciones del gabinete de prensa}

En un principio, bajo el paraguas de entidades públicas institucionales (gabinetes de prensa oficiales), poco más tarde abiertos a organizaciones representativas democráticas, y finalmente incorporados a las necesidades de las relaciones empresas-usuarios de productos (estableciéndose una estructura más global) a través de los gabinetes de comunicación. 
Pero con un punto en común con aquellos: la información y comunicación interna de las organizaciones.

En efecto, los gabinetes de prensa de organizaciones políticas, por ejemplo, cubren a menudo labores de comunicación interna; informando a militantes sobre actos, acuerdos, elecciones internas y declaraciones de líderes; también sobre trabajos de las áreas de educación, sanidad, economía, política parlamentaria, vivienda, seguridad ciudadana, empleo, etc.; o en épocas electorales, con seguimientos informativos sobre declaraciones de adversarios, incidencia propia en medios, elaborando resúmenes de prensa o audiovisuales, y finalmente poniendo al servicio de la organización el archivo y documentación. Es decir, se comporta más como gabinete de comunicación que exclusivamente de prensa.

Esta labor de comunicación interna también es propia, o mejor, es inherente a la empresa privada, como básica dentro de su estrategia de comunicación global o integral dirigida a sus diferentes públicos, en la que es sustancial la orientada a sus recursos humanos, para adaptarles a los cambios del entorno (Elías y Mascaray, 1998).

Ramírez (1995a) en un trabajo de investigación referido a la presencia, credibilidad y eficiencia de los gabinetes de prensa, revela que mientras en 1978 las informaciones políticas llegaban a los medios en un 30\%, en 1992 lo eran en un 52\% a través de estas estructuras. El trabajo productivo de la redacción en este mismo periodo se reducía del $44 \%$ al $22 \%$. Y respecto a presencia - credibilidad - eficiencia, por este orden y porcentaje los institucionales tienen: 67,2 - 56,5 - 85,9; los partidos políticos y sindicatos, 70,6 - 69-84,2; el mundo económico 70,6 - 65,3 - 80,7; y finalmente ONG y sociales 48,9 - 75,5 - 35,1. Lo que equivale a decir que la credibilidad entre los periodistas no es proporcional a la presencia ni a la eficiencia ${ }^{3}$.

Las organizaciones, cuando instrumentalizan estos dispositivos, persiguen la imagen positiva de una compañía o de una institución, en el objetivo de lo que se ve, se lea u oye, como la de todos aquellos que la representan o, dicho de otro modo, que la percepción de los públicos a los que se dirigen sea favorable a la entidad representada por la profesionalización de su estructura comunicativa (Martín Martín, 1995).

Emili Prado señala que "el control de la noticia no radica ya tanto en la propiedad de los medios como en la red de las fuentes... el control no solo depende de la propiedad" (ápud Martín Martín, 1995). Un hecho simple le avala, si pensamos en las informaciones regionales o locales lanzadas por los gabinetes de prensa. Al poder político-mediático le es más difícil descender a estos niveles, por lo que la sagacidad de los gabinetes les permitirá entrar como fuentes de información.

3 Soria (1991) explica que a menudo la información desde los gabinetes de prensa oficiales facilita las cosas a los periodistas, ya que hace que a medio plazo "el trabajo informativo resulte demasiado fácil y sencillo: caso podría decirse, en caricatura, que el informador puede limitarse a desfilar por sucesivas ruedas de prensa y agotar en ellas la mayor parte de su tiempo. Se puede llegar así a perder el hábito de buscar, contrastar y elaborar información personalmente". 
En este sentido, nuestras referencias a los factores de incidencia son resumidas por Costa $\mathrm{i}$ Badia (ápud Ramírez, 2011), cuando destaca como hecho clave de los gabinetes "sobrepasar las sucesivas barreras que interponen las organizaciones informativas antes de que el mensaje sea finalmente difundido". Y esta es la clave para acceder a los medios: situarse metafóricamente en la mesa de redacción misma, conseguir que esa distancia entre el medio y el gabinete se reduzca, cuasi "suplantando" al periodista, convirtiéndose en su más fiel colaborador, de manera que el gabinete consiga trasladarse virtualmente al propio medio.

Los gabinetes de prensa sitúan las noticias sobre las agendas de los medios de comunicación. Anticipando día y hora de las noticias y condicionando el factor sorpresa de las mismas. En resumen, podemos decir que los gabinetes han venido a cambiar las funciones que intervienen en el proceso comunicativo, en tanto intermediarios de la información y que una información del tipo que sea (elaborada por un gabinete) puede traspasar las barreras del medio sin mayores dificultades. La producción de los gabinetes de prensa viene muy bien a las empresas periodísticas, pues con el ahorro de trabajo hay otro ahorro: el del coste de personal para el medio. En especial cuando se reducen plantillas y sobre todo a medida que bajamos el nivel de la información a lo local y regional, donde los medios de comunicación disponen de menores medios económicos.

Este panorama alarma a muchos académicos y autores por la pérdida del sentido crítico de la profesión periodística, unido a la concentración de medios y la proliferación de grupos de comunicación, la información-espectáculo y las "dictaduras de las audiencias":

- El poder político que ha intentado controlar siempre la información recurre ahora a las fuentes.

- El poder apuesta por los gabinetes de prensa.

- Se produce una privatización de una información que teóricamente debería ser pública.

- Se produce el control de los elementos fundamentales de la noticia (el quién, qué, cómo, cuando y por qué) o reglas conocidas como las "5 W" en los géneros periodísticos informativos (Warren, 1975).

- Se imponen la concentración de medios, la información-espectáculo, la dictadura de las audiencias, las imposiciones del mercado y gracias a los gabinetes de prensa, también la información se concentra cada vez más (Miguel de Bustos, 1995).

Emili Prado plantea ciertas medidas para garantizar la independencia de la profesión y no perder el carácter crítico del oficio periodístico: "Agudizar las conciencias profesionales de los periodistas, favorecer el contraste informativo, no sucumbir con tanta facilidad a la inercia de las rutinas periodísticas, potenciar la discriminación positiva hacia las fuentes menos poderosas e intentar que cada medio cultive su propia agenda temática" (ápud Ramírez, 1995a).

Llegado a este punto, ¿mediante qué medios podemos hacer llegar la información del gabinete? Lo podemos realizar de la siguiente forma:

a) Vía telefónica directa: Mediante declaraciones, entrevistas para prensa, informacióncorroboración de la fuente sobre un hecho concreto. Aquí el gabinete puede actuar de 
portavoz e incluso como voz autorizada declarar en nombre de persona representada.

b) Vía directa por télex (en desuso), telefáxica (en desuso), correo electrónico: Comunicados a medios, convocatorias, declaraciones, contramanifestaciones o contradeclaraciones, artículos de opinión.

c) Directa por conexión radiofónica: Por línea microfónica a través de red telefónica, entrevista en directo para programas o informativos.

d) Línea telefónica a través de mezclador portátil (en desuso): Declaraciones en directo o diferido. Envío de información registrada por el gabinete a controles centrales.

e) Línea telefónica a través de RDSI: Igual que la anterior, aunque permite actuar como estudio de radio para entrevistas y conexiones con programas. Se requiere de unas mesa de mezcla, microfonía, grabadores e híbrido telefónico incorporado a la mesa o audiocoded (híbrido digital) autónomo.

f) Vía indirecta a emisoras de TV: Informaciones elaboradas y registradas por el gabinete, declaraciones registradas, reportajes.

g) Vía directa a los agentes de la información: Concesión de entrevistas personales a medios, ruedas de prensa y declaraciones a priori y a posteriori a los mismos.

Es también posible disponer de estudio propio de televisión, con postproducción propia, lo que equivale a decir que se pueden elaborar tiempos informativos para el ajuste en la redacción y montaje o para facilitar la presentación y off en directo de los espacios de noticias ${ }^{4}$. Además de estas formas de envío, podemos servirnos de los protocolos de archivo RTSO y FTP, y con programas como Acoustica Premium, Audacity u otros como Sound Studio 3.5.4, Cubase, Logic Audio (para montaje de audio) y los "Nero 11", "Adobe Premier", "Final Cut" (Mac), Windows Movie Maker, Magic Video De Luxe 16 Plus (para edición de video), por citar algunos.

Los gabinetes de prensa cumplen además otras funciones. Conviene advertir que dependiendo del tamaño de la organización, el jefe de prensa puede contar con una oficina, cuyo personal realice el vaciado de prensa (recortes de prensa de interés para la organización), le ayude a distribuir las notas, comunicados, atender llamadas, recopilar documentación, etc. reservándose para sí las funciones más relevantes: atenciones personales, despachar con la alta gerencia, organizar y elaborar planes de trabajo. Entre otros cometidos podemos señalar:

\footnotetext{
4 Esto no gusta actualmente a determinados profesionales, que ven sustituida sus funciones, por ejemplo, durante las campañas electorales, lo que por el contrario viene bien a las estructuras comunicativas de los partidos, pues pueden incluir sus informaciones en medios con menores recursos técnicos y de personal. Al hilo de esta diatriba, Del Riego (2008) considera que la influencia sobre la noticia es poca, ya que la información se limita a la frase de turno de una campaña (que el líder quiere colocar) y los periodistas "seguimos como perros falderos los intereses de los políticos". Cuando un líder visita una ciudad, la maquinaria la prepara en tensión días antes y llegado el acto tiene "un reflejo en los medios de comunicación como si de publicidad se tratara... ¿es necesario, con los actuales medios de comunicación (Internet) seguir una campaña electoral? Que la campaña electoral es el periodo en que el periodismo más se parece a la propaganda y menos a la información es algo sabido y desgraciadamente asumido por todos: partidos, políticos, periodistas y medios".
} 
- Escribir artículos de opinión a diferentes miembros de la organización: En el caso de las organizaciones políticas a diferentes responsables de áreas o parlamentarios con responsabilidades y portavocías de economía, educación, seguridad ciudadana, medioambiente, energía, así como dar a conocer los trabajos de las comisiones. Estos artículos de opinión llevarán la firma de la persona responsable de cada uno de esos apartados 5 .

- Colocar estos artículos en los diferentes medios: Teniendo en cuenta que no se puede reproducir el mismo artículo de opinión en diferentes cabeceras, pues ello iría en detrimento de la eficacia y se perdería credibilidad ante el medio y, sobre todo, exclusividad. Al medio le interesa esa opinión si es de su exclusividad. Por lo que son tácticas adecuadas alternar con medios o centrar diferentes opiniones sobre el mismo tema cuando interese, enviándoselo (entonces sí) a los diferentes medios con la misma firma.

- Escribir discursos: A la organización y a sus máximos representantes, preparándolos con citas adecuadas a la temática.

- Escribir entrevistas pactadas: Caso de suplementos especiales de colectivos profesionales, sectores industriales, entre otros. En este caso se puede pactar con un anuncio o colaboración publicitaria con el suplemento o una entrevista. El jefe de gabinete puede realizarla con el cabeza de la organización y enviarla al medio para su publicación 6 .

- Intervenir como portavoz de la organización: Hacer declaraciones ante peticiones de la prensa en nombre de otras personas. Esto sólo es posible en el caso de prensa. En radio y televisión sólo puede hacerse como portavoz, pero no en nombre de otras personas.

Es esta una de las funciones de los jefes de prensa (en tanto se escribe para otros) el anonimato $^{7}$. La dificultad, salvo los testigos, estribaría en demostrar que esos escritos

\footnotetext{
5 No hay que olvidar que los jefes de prensa son intermediarios de comunicación, por lo tanto tienen los conocimientos profesionales para escribir en el medio por encima de las personas que representan. En todo caso, estas sí deberán dotar de las ideas y documentaciones oportunas que den basamento al responsable de prensa para la realización de los escritos.

6 El caso extremo (pero posible de hecho, cuando el jefe de prensa es de máxima confianza profesional y conoce a la perfección a la organización y su representante) es cuando la entrevista la realiza el jefe de prensa preguntando y respondiendo a la vez, "suplantando" al entrevistado. Este sólo tendrá que dar el visto bueno a la entrevista, antes de ser enviada al medio.

7 Como anécdota que ilustre la labor de un jefe de prensa, voy a señalar un caso experimentado personalmente. El hecho aconteció siendo jefe de prensa del Simposio Internacional de Esculturas al Aire Libre, cuando Madrid fue designado Capital Europea de la Cultura (1992). En dicho simposio se instalaron obras de los grandes macroescultores del mundo, entre ellos el único que ha colocado una escultura en la luna, el belga Van Hoeydonck.

Fui encargado de escribir el texto correspondiente al entonces alcalde Agustín Rodríguez Sahagún que sería incluido en la publicación oficial del evento. Meses después, un periodista y escritor (Ángel del Río) se refiere en el libro dedicado al ex-ministro y ex-alcalde: "De las obras con que este alcalde ha podido contribuir para el futuro de los madrileños, pocas le dejan tanta satisfacción como aquellas que tienen que ver con el espíritu, con el quehacer artístico".
} 
corresponden al jefe de prensa; poco importa, pues es algo convenido en la profesión que corresponde a estas labores. Lo único demostrable es que uno estaba allí como responsable de ese gabinete ${ }^{8}$.

\section{Géneros empleados}

A continuación, detallaremos algunos géneros básicos en el trabajo de difusión de las organizaciones:

\subsection{Nota de prensa ${ }^{9}$}

Esta forma de comunicar es considerada un género periodístico por León Alonso (1995): "Querer incluir la nota de prensa como un género más dentro de la teoría general periodística no es algo aleatorio, sino que proviene de una imperiosa necesidad de hacer justicia, precisamente en unos momentos en los que darle prioridad al texto, al discurso periodístico, es lo que preconizan los modernos métodos científicos de la Periodística con respecto a la información de actualidad... hay que tratar de que se le dé el mismo tratamiento a lo que se ha considerado género periodístico hasta ahora y a lo que desde ahora también puede empezar a formar parte de ese capítulo de la Periodística”.

La redacción debe adaptarse a ciertas pautas "que no guardan relación con la gramática tradicional ya que no se atiene a sus reglas de construcción... La única norma es que cubra el máximo de objetivos con el mínimo de elementos [...] el lead (regla de las $5 \mathrm{~W}$ ) o párrafo inicial debe servir para presentarle al lector aquel o aquellos datos fundamentales, gracias a los cuales dicho lector podrá continuar o abandonar la lectura por razones de tiempo o de un mayor interés por otras informaciones [...] la habilidad expresiva del redactor debe conducir a que su texto o discurso resulte comprensible a base de un uso tan correcto de la gramática que desemboque en la más absoluta claridad de unas ideas que van a quedar reflejadas en el modo de exposición".

Estas ideas expresadas en la nota de prensa deberán tener en cuenta principalmente, respecto al léxico, un lenguaje funcional, claro, correcto y preciso; no usar neologismos, barbarismos o vulgarismos; no recargar el texto de adjetivos y de adverbios. Respecto

\footnotetext{
8 De todos es sabido (años más tarde eso sí) que la famosa frase que pasó a la historia de Adolfo Suárez, como flamante primer presidente de la Transición ("Puedo prometer y prometo") lo compuso Fernando Ónega, periodista que trabajó para él en esos momentos. Y que hoy lo sabemos porque lo ha contado el propio periodista, sin que en ningún momento lo desmintiera ni el propio Suárez ni personas de su entorno. Por tanto, el mejor reconocimiento que puede hacerse a estos profesionales es la humildad con la que trabajan desde el anonimato para otros.

9 Al referirse a los orígenes de los gabinetes de comunicación en España, Ramírez (1995b) reconoce dos posiciones: la primera de Pere Oriol Costa i Badia, que lo relaciona con la denominada "cultura del marketing". Bajo esta perspectiva, es el mercado el que genera el fenómeno. La segunda, la del sociólogo Jesús Ibáñez, situaba su origen en el ámbito de las Relaciones Públicas.
} 
a la organización de frases: descriptivas y no interpretativas; correcta sintaxis, evitar explicaciones perifrásticas y frases alargadas innecesarias. En cuanto al texto: adaptación al tipo de lector, evitar frases hechas y tópicos informativos, evitar transferencias de otros lenguajes cuando no sean necesarios, explicar términos y contenidos técnicos que puedan no entenderse; no usar abreviaturas, ni siglas que no se antecedan con su significado completo. La nota de prensa, para León Alonso, debe ser "enunciativa, categórica y escueta".

Ahora bien, ¿qué formato debe tener la nota de prensa? Esta tiene que persuadir: los periodistas quieren saber quién pone "rostro" a lo que allí se dice. Por esta razón, es preferible una nota que incluya declaraciones antes que un frío comunicado despersonalizado. Además, la nota ha de ser atractiva ${ }^{10}$ : llevará titulares (título y subtítulo) que despierten el interés. Pueden ponerse en negrilla nombres y declaraciones, pudiendo ir estas además en cursiva. Los textos pueden escribirse por bloques separados por interlineado.

Este formato no afecta al contenido ni tampoco a la publicación. Es simplemente una forma de hacerlo atractivo, ya que el redactor lo adaptará al medio con sus interlineados propios y su forma seguida para la lectura. Como una de las normas para un gabinete que se precie es facilitarle al máximo al medio la publicación, debe procurarse (en el caso que se entregue en papel) diseñar un formato para que el redactor lo "pique" y adapte inmediatamente al de la publicación. En el caso de entrega personal de un texto escrito, es útil acompañarlo con un $\mathrm{CD}$ o pen drive con la misma nota de prensa y un soporte gráfico para ilustrarlo. En el caso del envío por e-mail, al texto también se le debe adjuntar el contenido gráfico.

\subsection{La entrevista}

Respecto a este género, hay que tener en consideración algunas recomendaciones, fuera de las propias del género, uno de los más difíciles de la profesión periodística y que corresponde analizar en otros estudios. No obstante, puesto que en este género un periodista que se precie llevará un objetivo básico, además de las documentaciones oportunas y las referencias a la actualidad (muy probablemente para conseguir una primicia), desde el gabinete se tendrá en cuenta:

- El medio y su orientación.

- La relación con el redactor.

- El objetivo de la entrevista.

- Su lugar de de ubicación.

- La duración de la misma.

- Su oportunidad.

- La audiencia estimable.

10 Es un error enviarla con el formato de prensa, ya que una nota en este formato no es atractiva para la lectura en las salas de redacción. 
Con estos elementos, el gabinete confeccionará un cuestionario (que alberga preguntas pertinentes y de interés) y que presumiblemente realizará el periodista entrevistador. El responsable del gabinete ha ejercido (en igualdad de condiciones) el papel que el ahora entrevistador y por tanto puede ponerse en su lugar para advertir y orientar al responsable de la organización-entrevistado acerca de las preguntas que más interesarían al entrevistador.

No es aconsejable solicitar un cuestionario previo al medio, ya que esto pondrá en guardia al periodista sobre la organización y va en detrimento de la frescura y espontaneidad de la entrevista. Una vez advertido sobre esta cuestión, el jefe de gabinete dará todas las facilidades al periodista, pudiendo estar presente o no durante la entrevista.

Si se concretase el primer caso, el jefe de gabinete permanecerá de "convidado de piedra" y sólo intervendrá como persona de confianza que es para aclarar algún concepto que el periodista no le quede claro o algún olvido de importancia del entrevistado y que convenga ampliar.

\section{Medios operativos de los gabinetes de prensa}

En línea con facilitar el trabajo a los periodistas, resulta importante que los gabinetes ofrezcan los instrumentos personales, materiales y espaciales ${ }^{11}$. Pongamos por caso un Parlamento Autonómico y el de una sesión parlamentaria no rutinaria, donde van a intervenir los portavoces y se va a debatir un tema de gran interés público (incluyéndose interpelaciones al Presidente de Gobierno, sus réplicas y la de los líderes de la oposición). El gabinete habrá previamente convocado a los medios para la sesión, habrá dado facilidades para la acreditación oportuna. Les dotará de documentación sobre el orden del día, el turno de intervenciones, etc.

Durante la sesión, los ubicará en un lugar cómodo para poder seguir in situ la sesión parlamentaria. Del mismo modo, facilitará a los periodistas gráficos el momento en que pueden realizar las fotos. En la "sala de prensa" colocará monitores con audio para poder seguir las sesiones en lugares próximos a la redacción y facilitará cualquier otra necesidad que los periodistas del arco parlamentario puedan tener en el uso de sus funciones.

\footnotetext{
11 En el caso del Parlamento Andaluz, el jefe de prensa ha gestionado el montaje de un sistema de realización televisiva para evitar la proliferación de cámaras en el interior del Pleno. El dispositivo sirve tanto para la emisión en directo de las sesiones por Canal Sur Televisión, como para el registro de los informadores, quienes también pueden realizar entrevistas en el exterior del edificio de sesiones con sus propios medios. Para la radio se dispone de cabinas para conexión en directo por parte de los redactores con sus medios, pudiendo tener asimismo sonido directo en dichas cabinas. Otro servicio que prestan es el de audio, imagen o foto documental posterior.
} 


\section{Off the record y primicias informativas}

En la relación de los gabinetes con los medios, el responsable de prensa debe conocer en profundidad a la institución que representa, así como los medios a los que va a dirigirse. En el caso de las informaciones off the record, deberá extremar el cuidado con las que son entendidas como tal y no sólo por su parte, sino de las que ofrezcan off the record a los periodistas, las personas para las que trabaja.

Las primicias, por su parte, son un tema controvertido. Mantenemos la posición que sí pueden darse, pero dosificándolas, es decir, reservando diferentes primicias para otros medios y sólo en ocasiones. En el caso concreto de una ciudad que cuente con tres periódicos, a lo largo de un periodo anual pueden existir varias que se van lanzando a los periodistas. Si se realiza adecuadamente, cada uno de ellos puede tener su parte y no molestarse ninguno. Siempre quedará, además, como mérito del medio.

\section{No ocultar lo inocultable}

Es igualmente relevante (lo que en términos de la organización directiva de la comunicación conllevaría a un "manual de crisis" que excede este trabajo) tener en cuenta no desacreditar a la organización intentando tapar con la mano el torrente de agua informativa que nos excede ante un hecho negativo para la organización.

Hemos sostenido que es muy importante, para el éxito de un gabinete, el prestigio profesional y la confianza que genere el mismo de cara a los medios. No se puede estar sólo para los buenos momentos, para aquellas informaciones que necesitemos "colocar" en el medio adecuado. Hay ocasiones (sobre todo en las informaciones políticas e institucionales, también en las empresariales) que han acontecido sucesos no convenientes y que por uno u otro modo es del conocimiento de los medios. Ocultar estas informaciones va en detrimento de la credibilidad.

La prensa no está sólo a la espera de lo que se le quiera informar, también quiere saber acerca de determinados hechos o conocer la opinión de determinada institución o empresa sobre una situación económica, una noticia del sector, una frase emitida por un adversario político, etc.; en todos esos casos se debe estar abierto cuando se nos requiera y hacer entender a los dirigentes que se represente que deben ser abiertos.

\section{El seguimiento informativo y el resumen de prensa}

El jefe de prensa (bien con sus propios medios o con su equipo de colaboradores) deberá realizar un seguimiento informativo como forma de tener un control y poder evaluar los resultados y eficiencia de su gestión. Deberá archivar estas informaciones por fechas y temáticas, elaborando así un Press Book o encuadernación sencilla de las noticias para ser consultado en cualquier momento y estar a disposición de la organización. 
Con frecuencia (en organizaciones políticas, empresariales o institucionales de envergadura) realizará el vaciado diariamente, es decir, el resumen de prensa del día en torno a la organización. Este deberá de estar listo a primera hora de la mañana para pasarlo a los responsables de la organización y puedan conocer las noticias que afectan a su entidad.

Algunas organizaciones, además, requieren otras noticias del sector o afines (e inclusive de la competencia) para tener una información precisa del estado de la cuestión que les permitan tomar decisiones de interés en provecho propio.

\section{Investigar para la organización}

Se trata de otra de las facetas exigidas a menudo a los gabinetes de prensa (tanto institucionales como empresariales) que consiste en recabar información acerca de competidores u otros contenidos. Suelen encargarse estos trabajos a las personas habituadas a la administración de información. Supongamos que estamos al frente de un gabinete que trabaja en el sector inmobiliario industrial y existe interés por intervenir en un polígono o parque empresarial. En ese sentido, se requerirá información sobre polígonos en localidades próximas, precios de venta en el mercado para naves similares, calidades, niveles de población, renta per cápita, empleados, porcentajes de edades, escuelas, industrias, sectores emergentes, entre otros.

Todo este tipo de información puede solicitarse al gabinete para su estudio por los responsables de la organización y tomar decisiones. Supongamos ahora que se trata de una organización política que quiere saber los tiempos que se destinan al gobierno, al partido gobernante y a la oposición en una televisión pública. Encargará también al gabinete el seguimiento durante un periodo determinado, bien con datos propios o con el análisis de los tiempos informativos obtenidos por otras fuentes. Esto es de mucho interés para los políticos y motivan notas de prensa, declaraciones y contradeclaraciones.

\section{Rueda de prensa}

Conforma una ocasión excelente para tener contacto personal con los periodistas y para dar a conocer un hecho relevante de la organización, bien sea una propuesta como proposición de ley o no de ley de un partido político; o ante una situación grave del país (un atentado por ejemplo) o bien en el caso de una empresa, la presentación de un producto. Puede servir asimismo a colectivos profesionales (colegio de médicos, de ingenieros industriales, etc.). Estas son las cuestiones que tiene que tener en cuenta el jefe de prensa ante una convocatoria:

- Selección del lugar: De fácil acceso y aparcamiento, pudiendo ser el salón de actos de la sede de la organización si se posee.

- Condiciones del local: Acústica y lumínicas. Un local con tiempos de reverberación por encima de lo aconsejable para actos públicos será inadecuado por la poca inteligibilidad. Lo mismo por la falta de iluminación, que dará mala imagen de entrada.

- Día y hora: Habrá de asegurarse que no coincida con otro gran acontecimiento o 
convocatoria que pudiera restar asistencia. Asimismo, debe realizarse a una hora que facilite la información con respecto al horario en que se ubique dentro de la parrilla de información, los informativos radiofónicos y televisivos.

- Convocatoria: Con el tiempo suficiente para situarla en las agendas de los periodistas. Esta deberá llevar un anticipo informativo sobre el porqué de la rueda de prensa que sirva de atractivo a la convocatoria, pero no lo suficientemente extenso. Eso sería un error, pues evitaría la presencia del redactor que utilizaría el texto enviado para ahorrarse acudir personalmente. Dicho de otro modo, debe llamar la atención para motivar la presencia.

- Seguimiento de la convocatoria: Que ha llegado a la sección y a la persona correspondiente. Se recomienda realizar un recordatorio un día antes o inclusive el mismo día si da lugar.

- Atención personalizada a los periodistas que acuden: A través del jefe de prensa o de la azafata que entrega documentación.

- Documentación: La carpeta deberá llevar documentación de interés sobre el objeto de la rueda de prensa. Es importante acompañar una nota de prensa escrita con declaraciones de la persona que la da, acompañada de un CD con la misma nota, más ilustraciones gráficas en relación al objeto de la rueda de prensa. Este hecho es muy importante pues aunque los periodistas pregunten, es muy posible que a la hora de llegar la redacción les sea más fácil picar lo ya escrito por el gabinete que ponerse a redactar, sobre todo si tienen que hacerlo con más informaciones.

- Declaraciones a priori: Se darán en aquellos casos (como en los programas de televisión) que por el horario precisen editar la información y sólo cuando lo pidan.

- Presentación del convocante: El jefe de prensa deberá realizar la presentación de quién o quienes se sienten en la mesa, pues puede que haya periodistas que han sustituido a sus compañeros por cualquier circunstancia y no los conozcan.

- Dar el turno de preguntas: Una vez concluida la intervención del representante de la organización, el jefe de prensa dará la palabra a los periodistas, identificándolos con el medio o solicitando que se identifiquen para que el representante de la organización sepa a quién se dirige.

- Intervenir en caso de pregunta inconveniente: Sólo en el caso de que pueda suponer que la rueda de prensa se desvíe de su objetivo, el jefe de prensa estará al quite para que (de manera diplomática) salve la jornada. Es importante que lo haga de manera que no cree malestar en el resto ${ }^{12}$.

- Despedir la rueda de prensa: Cuando el jefe de prensa ha detectado que se han tratado todos los temas de interés, da por cerrada la rueda de prensa con el agradecimiento a todos los presentes por su asistencia.

- Declaraciones a posteriori: Terminada la rueda de prensa, algún periodista puede necesitar una cuestión o aclaración posterior o (en el caso de las televisiones y las radios) quieran incluir una declaración adicional a fin de adecuarse al tiempo asignado para la información. El jefe de prensa facilitará estas declaraciones a posteriori, procurando que se realice sobre el fondo adecuado, donde aparezca el logo de la organización.

12 Ante este tipo de situaciones, es oportuno emplear fórmulas como: "Disculpa ese es un tema que no es objeto de esta reunión. Terminada la rueda de prensa, no habría inconveniente en que personalmente responda a tu pregunta", y se da la palabra al siguiente periodista. 
- Invitación: Al término de la misma se invitará a un ágape según el horario. Esto se indicará en la convocatoria. Este detalle es muy de agradecer por los periodistas a determinadas horas y sirve para tener una relación más informal y personalizada con los mismos.

- Elementos visuales: Deberán contemplarse pancartas de mesa o de pared, a buena distancia para tiros de cámara y fotos que garantice que el motivo de la rueda de prensa o el logo de la organización se incluya en la toma.

- Otros elementos técnicos: El jefe de prensa deberá tener en cuenta un lugar para las cámaras y facilitar (mediante sistemas de conexiones múltiples) la toma de sonido para cámaras y emisoras con la idea de no llenar la mesa con los micrófonos de la emisora de radio y televisión y los grabadores de la prensa. Deberá facilitar, asimismo, una sala de redacción con ordenadores, teléfono, entre otros, para el envío desde el lugar de celebración de las informaciones de la rueda de prensa.

- Servicios a medios no asistentes: El jefe de prensa contactará (y en algunos casos pactará previamente) con aquellos medios que les haya sido imposible la asistencia, el envío de la información o una entrevista telefónica. En el caso de la televisión, si la organización no dispusiera de medios propios, lo garantizará a través de alguna de las agencias asistentes.

\section{Los gabinetes de prensa en campañas electorales}

En las organizaciones políticas representan un momento clave, ya que los jefes de prensa de los candidatos están en muy estrecha relación con los mismos, facilitándoles la campaña. No es de su jurisdicción, aun cuando lo aconsejable es que formen parte del equipo de consejeros previos a la campaña, formar parte de las decisiones sobre los mensajes, a nivel general, que el partido político elija. Esto suele estar supeditado al responsable de comunicación, con cargo político dentro de la ejecutiva de la organización, cuyo comité electoral junto a la cúpula dirigente deciden el programa electoral y la campaña, situando a un jefe de campaña al frente.

Lo normal es que "la estrategia publicitaria" de la misma descanse sobre una empresa profesional, a la que se le encarga la elaboración de los mensajes fundamentales, para conseguir el éxito propuesto con antelación. Esta deberá de ser coherente y consecuente con lo que la organización haya desarrollado en los cuatro años anteriores de Legislatura. Puede ocurrir que se encargue a un profesional de confianza la organización, la trastienda de la campaña, que será el que marcará las directrices generales que encargará a la empresa con los elementos disponibles al uso (mensaje central, logos, colores, diseño creativo, rostros) y expresados en programas electorales, folletos, pegatinas, merchandising e intervenciones en los medios, que estarán supeditados a las directrices generales de la estrategia.

En el caso de las organizaciones regionales y locales, con estas normas generales se elaborarán las propuestas más cercanas a los ciudadanos que (en el caso de los municipios) se harán confluir las específicas con las emanadas desde la organización centralizada. Una vez establecido este marco y elaborado el calendario de intervención de los candidatos y los lugares (cuya responsabilidad recae en la organización, según el interés para captar el 
voto) los jefes de prensa locales, que estarán en contacto permanente con los regionales y nacionales, elaborarán el planning de actos para hacérselos llegar oportunamente a los periodistas que van a cubrirlos. Así, deberán por tanto conocer quiénes son los seleccionados por el medio para facilitarles la labor en los actos o mítines, y los que intervienen (acompañando a nivel regional y local) a los grandes líderes.

En el caso de la campaña nacional, los líderes de las formaciones suelen ir en caravanas organizadas, en las que van acompañando a los mismos, así como a los periodistas destacados por el medio. Los jefes de prensa locales, en estos casos, velarán por la situación en los actos de estos "periodistas de caravanas" sin menospreciar a los locales, que también informarán del evento y que son los que informan más o menos diariamente sobre las noticias más cercanas de la formación.

En el desarrollo del mitin hay que tener en cuenta las conexiones posibles en directo de las televisiones, facilitándole al candidato un monitor o una señal cuando se establece la conexión, momento en el cual el candidato aprovechará para dar un giro al mensaje y difundir aquello que se ha planteado desde la elaboración de la campaña. En el caso de los medios con menos recursos personales, los jefes de gabinete (transcurrido el acto) enviarán las informaciones de los actos que deberán ser previamente pactadas. Facilitarán asimismo las conexiones con los equipos de sonido, las condiciones de iluminación, el atrezzo de campaña, que en el caso de los candidatos nacionales viene organizada por los servicios centrales. De no ser así, velarán por todo lo que tiene que ver alrededor del mitin: acceso, aparcamientos, escenario, microfonías y equipos de sonido e iluminación; sistemas de conexión para radio y televisión; teléfonos, lugar de redacción y demás facilidades que puedan tener los que van a informar de la campaña.

Todas las atenciones que se den a los periodistas que siguen al partido redundan en la buena imagen de la organización y, por tanto, predispone favorablemente a los periodistas. Entre ellas no menos importantes serán las condiciones de iluminación del escenario, del público asistente, el atrezzo para los tiros de cámara (pancartas traseras), atril, enaras, banderolas, etc. Dar facilidades para la colocación de las cámaras es muy importante, sobre todo en los cierres, que dará la última imagen del partido. Si bien esto se supedita al equipo de realización, un observador algo avezado comprobará las desiguales condiciones de un Presidente de Gobierno en funciones (que aspira a la reelección) y un candidato más modesto de una formación de oposición aspirante a gobernar, en especial del material técnico empleado, iluminación, unidad móvil, número de cámaras, etc. Podríamos preguntarnos si comunicación más campaña es igual a voto (comunicación + campaña $=$ voto).

En plena precampaña electoral, los partidos políticos engrasan sus maquinarias de comunicación a la caza del votante. Según las encuestas del votante indeciso, los grandes partidos de nuestro espectro parlamentario tienen en su organigrama responsables de comunicación, normalmente extraídos de la profesión periodística, aunque también de la comunicación audiovisual ${ }^{13}$.

13 Por encima de ellos se nombra un dirigente político, en no pocos casos sin vinculación directa con los medios, a los que se les "premia" con ese cargo, subterfugio que esconde una forma de apartarles de mayores aspiraciones. 
Los jefes de prensa, todavía así llamados en muchas organizaciones, duplican su trabajo en comunicación, pues han de estar al tanto de todo lo que se escribe o difunde por los medios, para tener al día a los políticos-candidatos, tanto de lo que se recoge sobre sus mítines y manifestaciones como de las referencias que los adversarios realizan, iniciándose así ataques y contraataques en estas particulares canchas en que se convierte la geografía nacional. Han de acompañar a los periodistas que cubren las informaciones que generan los grandes líderes en sus campañas, en las caravanas cuasi "circenses" que como los grandes artistas arriban en sus galas de pueblo en pueblo o de ciudad en ciudad, manteniéndolos informados en todo momento de las rutas, opiniones, y procurando hacer lo más cómodo posible el trabajo y la convivencia durante las intensas horas de viaje.

Algunos de estos partidos, además, actúan como auténticas productoras de noticias, con los medios técnicos propios para facilitar información en "tiempo real" a quien hubiere menester. Claro que no todo el monte es orégano: las organizaciones políticas más modestas han de extremar el cuidado y esfuerzo por abrirse un hueco informativo, dado que los medios no disponen de suficiente personal para dedicarlo al seguimiento de estos otros líderes menos mediáticos.

Estos jefes de prensa, cuando cumplen funciones más amplias, comunican internamente a líderes provinciales (de estructuras más básicas, pueblos o barrios) los mensajes y consignas de las campañas, facilitando los medios técnicos adecuados para que cumplan su función en sus respectivos territorios. Por tanto, realizan una labor de comunicación interna, permaneciendo de guardia con sus colaboradores para los asesoramientos oportunos. Dada las ocupaciones de los grandes líderes en estas fechas, escriben declaraciones a medios impresos, en su nombre, convirtiéndose en personas de contrastada confianza profesional.

De paso, la parafernalia informativa que se genera, por razones de las oportunidades políticas de cada grupo político, recae asimismo en los responsables de comunicación institucionales, de consejerías, delegaciones, etc., que tienen trabajo extraordinario para responder a colectivos y organizaciones ciudadanas (connotadas políticamente) que por mor de protestas o reivindicaciones, aprovechan que el Pisuerga pasa por Valladolid, arremetiendo contra los cargos institucionales afectos al Partido gobernante municipal o regional.

Los resultados de las campañas (todavía no nos igualamos a EE. UU.) se deciden por la comunicación con los ciudadanos y las respuestas a sus necesidades a lo largo de una legislatura. El conjunto del partido se organiza para ello, dando posibilidades participativas a sus militantes, en especial desde la oposición y no con sorpresas de última hora. Sólo el margen para la indecisión da, en contextos como el de España, margen para captar el voto en campaña.

Contreras (1996) plantea la discusión existente sobre el papel de los medios en las campañas electorales, en especial la televisión: "Año tras año los estudios e investigaciones que se realizan abren más incógnitas sobre la supuesta influencia decisiva que la televisión pueda tener en un proceso electoral. Por el contrario, la obsesión de los políticos y asesores por el control de las imágenes es cada vez más obsesiva". 
En unas declaraciones de Alberto Ruiz Gallardón, aparecidas en El País, el otrora Presidente de la Comunidad de Madrid explicaba cómo había confirmado su convicción de que esa influencia era ridícula: "He ganado unas elecciones con mayoría absoluta frente a una línea informativa de Telemadrid radicalmente contraria a nuestra candidatura" (ibídem). Y es que hay que considerar las diferencias culturales y de sistemas democráticos diferentes para entender las divergencias de influencia del medio en Europa y los Estados Unidos. "Si hubiera que resumir en una idea la tesis dominante en la materia que nos ocupa, dentro del mundo de la investigación internacional, cabría afirmar que se tiende a pensar que la televisión rara vez tiene un poder determinante en un proceso electoral, pero en ningún caso cabe predeterminar cuando se puede romper la norma general".

Refiriéndose a los Estados Unidos, Contreras aclara la cuestión, pues es allí "donde el interés sobre este asunto es casi obsesivo entre la clase política y el mundo de los medios. Hay que tener en cuenta que la riqueza del modelo televisivo norteamericano, unida al desinterés general de la ciudadanía por los procesos electorales, acentúan la importancia del posible fenómeno de influencia del medio sobre unos votantes escasamente enterados de la realidad política".

Con respecto a las caravanas electorales, Iglesias (2008) las considera obsoletas en España. Partiendo de la base que la prensa (además de informar, entretener y vender) debe descubrir la verdad, así como vigilar y controlar el poder político, la autora considera un régimen de dependencia mutua: "Los políticos necesitan de los periodistas para poder llegar a sus votantes potenciales... también los periodistas precisan de los políticos y deben saber buscar, conservar y preservar sus fuentes para conseguir una información fiable y de primera mano. Pues bien, si este equilibrio se rompe y es a costa de los intereses de los periodistas, estos se convierten en meros instrumentos y mensajeros serviles al servicio de los partidos políticos, en tanto que desatienden los de sus lectores, radioyentes y televidentes". Y esto es lo que ocurre cada vez más según su consideración durante las campañas electorales, apoyado por la velocidad vertiginosa de la información, eficazmente utilizada por los partidos, mientras los medios se han quedado anclados en situaciones pasadas.

A diferencia de procesos electorales anteriores (cuando las campañas se hacían en autobús, se recorrían muchos kilómetros y el margen del periodista era mayor) a pesar de tener menos medios para llegar su crónica a las redacciones, hoy los partidos "se han hecho los amos de la nueva realidad. Ellos han sabido sacar rentabilidad a las nuevas tecnologías para ponerlas a su servicio prescindiendo cada vez más, del filtro profesional. Los periodistas que viajamos empotrados en las caravanas electorales nos hemos convertido en unos simples mandados o, en el mejor de los casos, en meras comparsas que forman parte del atrezo [...] Los horarios y las actividades de campaña están diseñadas prácticamente en función de los tiempos de radios y televisiones [...] Se trata de no permitir margen de maniobra a los periodistas" (ibidem).

Los aviones privados les permiten a los candidatos celebrar más mítines en lugares distantes, alterando el programa, si es necesario, sin tener en cuenta las prioridades o conveniencia 
de los periodistas. Entre otros cambios y condiciones difíciles para el periodista, Iglesias (2008) cita la rapidez con que se produce los trabajos por la prevalencia del medio televisivo, haciendo imposible el contacto con los líderes locales, pues la caravana llega directamente desde el aeropuerto al polideportivo o a la plaza de toros y se sale inmediatamente después de haber enviado las crónicas. Además de que no hay lugar para la novedad y sacar tajada a las fuentes, los candidatos repiten el mismo discurso, los mismos chistes, etc., con alguna adaptación al nuevo lugar donde se da el mitin.

Del Riego (2008) estima que la influencia que puede ejercerse sobre la noticia es poca, ya que la información se limita a la frase de turno que el líder quiere colocar, "y los periodistas seguimos como perros falderos los intereses de los políticos". Cuando un líder va a visitar una ciudad la maquinaria la prepara en tensión días antes y llegado el acto tiene "un reflejo en los medios de comunicación como si de publicidad se tratara $[\ldots]$ ¿Es necesario, con los actuales medios de comunicación (Internet), seguir una campaña electoral? Que la campaña electoral es el periodo en que el periodismo más se parece a la propaganda y menos a la información, es algo sabido y desgraciadamente asumido por todos: partidos, políticos, periodistas y medios".

Sobre un estudio del CIS de enero de 2007 (que destacaba que en España se consume muy poca información política y que la poca que se consume se hace a través de la televisión y la radio; sólo el 17,2\% lee información política en la prensa diaria), Del Riego señala: "Lo fácil es decir que a los españoles les importa poco la información política... aunque paradójicamente en los medios sigue primando la información política... que siete millones de espectadores vean, y no digo vean, se sienten delante de un televisor y pongan el canal por el que emiten un debate entre Pedro Solbes y Manuel Pizarro acaba para siempre con ese tópico".

Además, siguiendo el Informe Anual de la Profesión periodística en 2007 de la Asociación de la Prensa de Madrid, un $84 \%$ de los encuestados asegura tener poco $(57,3)$ o ninguna $(26,6)$ confianza en la información política ofrecida por los medios de comunicación. "Al 59,7\% no le parece interesante la información ofrecida por los medios en campaña electoral, sí relevante al 39,3\%. ¿Qué estamos haciendo entonces? ¿Cómo queremos influir o vender periódicos, o que los partidos nos hagan caso, si al $60 \%$ de los que nos pueden leer no les parece interesante lo que les ofrecemos? [...] La conclusión de ese estudio es que si la información que los medios reflejan se encuentra politizada hasta el extremo de no reflejar realidades, sino de crear realidades alejadas de los intereses de los ciudadanos, pero cercanas a los intereses políticos, la desorientación y el descrédito que produce en los ciudadanos anula a los medios para la tarea de decisión del voto" (ibídem).

\section{Fuentes consultadas}

Arceo Vacas, J. (1988). Fundamentos para la teoría y técnica de las Relaciones Públicas. Barcelona: Promociones y Publicaciones Universitarias. 
Cárdenas Rico, M. (2000). Gabinetes de prensa municipales en la provincia de Sevilla. Sevilla: Diputación de Sevilla.

Cockerell, M. (1988). La televisión inglesa y los primeros ministros”. Madrid: Planeta. Contreras, J. (1996). “Elecciones y TV”. Revista Telos, núm. 44.

Del Riego, C. (2008). "Victimas o cómplices”. Revista Periodistas, num. 14, Asociación de la Prensa de Madrid.

Desantes, J. (1974). La Información como derecho. Madrid: Editorial Nacional.

Elías, J. y Mascaray, J. (1998). Más allá de la comunicación interna. Barcelona: Gestión 2000.

Iglesias, M. (2008). “Las obsoletas caravanas electorales”. Revista Periodistas, núm. 14. Asociación de la Prensa de Madrid.

León Alonso, R. (1995). "La nota de prensa, un género periodístico". Colección Pliegos de Información.

Martín Martín, F. (1995). Comunicación en empresas e instituciones". Salamanca: Universidad de Salamanca.

Miguel de Bustos, J. (1993). “Grupos europeos de comunicación”. Revista Telos, núm. 35.

Ramírez, T.

_(2011) "Gabinetes de Comunicación: de la seducción por la imagen a la obsesión por 'aparecer'. El periodismo de rutina hace más fuertes a las fuentes oficiales y más débiles a las no oficiales”. Extraída el 12/IX/2013 desde http://www.ehu.es/zer/hemeroteca/pdfs/ zer01-08-ramirez.pdf

_(1995a). "La influencia de los gabinetes de prensa". Revista Telos, núm. 40. Extraída el 12/IX/2013 desde http://sociedadinformacion.fundacion.telefonica.com/telos/anteriores/ num_040/opi_perspectivas3.html

_(1995b). Gabinetes de comunicación. Funciones, disfunciones e incidencia. Barcelona: Bosch Comunicación.

Soria, C. (1991). La hora de la ética informativa. Barcelona: Mitre.

Villafañe, J.

_(1999). La gestión profesional de la imagen corporativa. Madrid: Pirámide.

_(1996). “Imagen corporativa y management". Revista Telos, núm. 46.

Warren, K. (1975). Géneros periodísticos informativos. Barcelona: Editorial A.T.E. 